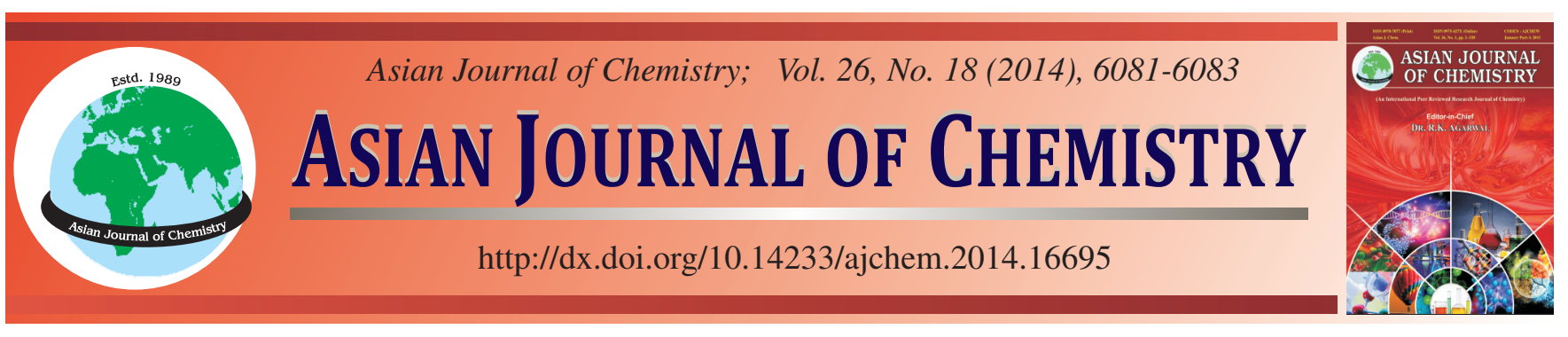

\title{
3,4-Dihydroisoquinolinium Trichloroacetatochromate: A Mild and Effective New Reagent for Oxidation of Alcohols to Carbonyl Compounds and Arenes to Their Quinones
}

\begin{abstract}
RECEP OZEN
Department of Chemistry, Faculty of Science, Mersin University, 33342, Mersin, Turkey

Corresponding author: Tel: +90 324 3610001; Fax: +90 324 36100046; E-mail: rozen@ mersin.edu.tr

A new chromium(VI) reagent, 3,4-dihydroisoqinolinium trichloroacetatochromate was prepared by reacting trichloroacetic acid with $\mathrm{CrO}_{3}$ in water. This reagent is suitable to oxidize various primary and secondary alcohols to the corresponding carbonyl compounds and anthracene to antraquinone in a good yields.

Keywords: 3,4-Dihydroisoqinolinium trichloroacetatochromate, Oxidation, Alcohols.
\end{abstract}

\section{INTRODUCTION}

The oxidation of organic substrates in aprotic solvents, under mild and neutral contitions, is important in modern organic synthesis. Therefore, the search for new oxidizing agents is of interest to synthetic organic chemists ${ }^{1-7}$. The representative chromium-based reagents play a vital role in organic chemistry as oxidants for alcohols 8 . For instance, the Collins reagent ${ }^{9}$, pyridinium chlorochromate ${ }^{10}$, pyridinium bromochromate ${ }^{11}$, cerium(III) bromate ${ }^{12}$, quinolinium fluorochromate ${ }^{13}$ have been devoloped for this purpose. There are several examples using supported organic molecules on solid support as a oxidizing agents such as silica gel, montmorillonite $\mathrm{K} 10^{14}$.

Recently, we have introduced 3,4-dihydroisoquinolinium chlorochromate (DIQCC). As an efficient reagent for oxidation of alcohols to carbonyl compounds and arenes to their respective quinones ${ }^{15}$.

In continuation of our study, we wish to report 3,4-dihydroisoquinolinium trichloroacetatochromate, a facile oxidation reagent primary, secondary and benzylic alcohols to their corresponding carbonyl compounds. At the same time, this reagent was used for oxidizing various arenes such as indane, tetraline, antracene, pheneanthrene compounds.

Some of the reported reagents suffer from disadvantages such as instability, hygroscopicity, low selectivity, long reaction time, difficulty of preparation and need for a large excess of the reagent. Thus, a mild, a more selective and inexpensive reagent is still in demand.

\section{EXPERIMENTAL}

Melting points were determined on Electrothermal $9100 \AA$ apparatus. IR spectra were recorded on a Win First Satellite ${ }^{\circledR}$ model spectrophotometer. ${ }^{1} \mathrm{H}$ NMR spectra were obtained using a $400 \mathrm{MHz}$ Bruker DPX® instrument. Chromium analyses were performed using UV-1601 Shimadzu® All products are known compounds; they were identified by comparision of their physical and spectral data with those of authentic samples. All reagent and solvents are of reagent grade. 3,4-Dihydroisoquinoiline was prepared according to literature ${ }^{16}$.

Preparation of 3,4-dihydroisoqunolinium trichloroacetatochromate: A solution of $\mathrm{CrO}_{3}(5 \mathrm{~g}, 0.05 \mathrm{~mol})$ in water $10 \mathrm{~mL}$ cooled to ${ }^{\circ} \mathrm{C}$ was added trichloroacetic acid $(8.15 \mathrm{~g}$, $0.05 \mathrm{~mol}$ ) in $50 \mathrm{~mL}$ glass beaker. The mixture was stirred to give an red-orange solution for 2-3 min. The solution was then cooled in an ice bath $\left(0-5{ }^{\circ} \mathrm{C}\right)$ for $5 \mathrm{~min}$ and 3,4-dihydroisoquinoline $(6.58 \mathrm{~g}, 0.05 \mathrm{~mol})$ was added portion wise and the mixture was stirred at $0{ }^{\circ} \mathrm{C}$ for $1 \mathrm{~h}$. The cold mixture was filtered on a sintered glass funnel and the red-orange solids were collected. The product was dried in vacuum desicator over $\mathrm{P}_{2} \mathrm{O}_{5}$ to give 3,4-dihydroisoquinolinium chlorochromate in $90 \%$ yield. The reagent decompeses at $100{ }^{\circ} \mathrm{C}$. IR $(\mathrm{KBr}$ pellet) $\mathrm{cm}^{-1} 3442$, 3055, 1678, 1238, 962, 883. Anal. Calcd. For $\mathrm{C}_{11} \mathrm{H}_{10} \mathrm{NO}_{5} \mathrm{Cl}_{3} \mathrm{Cr}$ : C, 33.49; H, 2.55; N, 3.55. Found: C, $33.20 ; \mathrm{H}, 2.50 ; \mathrm{N}, 3.60$. The acidity of 3,4-dihydroisoquinolinium chlorochromate is at pH. 2.4 in $0.01 \mathrm{M}$ aqua solution. 
Oxidation of alcohols to carbonyl compounds: A solution of the organic compounds (Table-1, $10 \mathrm{mmol}$ ) in $10 \mathrm{~mL}$ of dichloromethane was added to 3,4-dihydroisoquinolinium chlorochromate (Table-1, 1:1 ratio; $3.94 \mathrm{~g}, 10 \mathrm{mmol}$ and 1:3 ratio; $11.83 \mathrm{~g}, 30 \mathrm{mmol})$. The mixture was stirred magnetically at room temperature until the complete consumption of the substrate. The progress of the reaction was monitored by TLC analysis. After completion of the reaction, $50 \mathrm{~mL}$ of water was added to the reaction mixture and extracted with ether $(3 \times 20 \mathrm{~mL})$. The combined organic layer was dried over $\mathrm{MgSO}_{4}$ and evaporated on a rotary evaporator under reduced pressure. Then the product was chromatographed over silica gel using ethyl acetate-hexane (1:4) as the eluent to separate the product. After evaporation of the solvent, the fairly pure solid were crytstallized out the liquid carbonyl compounds were derivatized with 2,4-dinitrophenylhydrazine. The melting points of solid compounds such as benzil, benzophenone, 3-oxocholestorol, 1-menthone, 1-indanone, tetralone, 10-anthraquinone and phenanthrene-9,10-quinone were checked and these compounds were identified by spectral data like IR and ${ }^{1} \mathrm{H}$ NMR.

\begin{tabular}{|c|c|c|c|c|c|}
\hline \multicolumn{6}{|c|}{$\begin{array}{c}\text { TABLE-1 } \\
\text { OXIDATION OF ORGANIC SUBSTRATES WITH } \\
\text { 3,4-DIHYDROISOQUINOLINIUM CHLOROCHROMATE }\end{array}$} \\
\hline Entry & Substrate & Product $^{d}$ & $\begin{array}{l}\text { Substrate } \\
\text { /Oxidant }\end{array}$ & $\begin{array}{l}\text { Time } \\
\text { (h) }\end{array}$ & $\begin{array}{l}\text { Yield } \\
(\%)\end{array}$ \\
\hline 1 & $n$-Butanol & Butanal & $1: 1$ & 0.5 & $98^{\mathrm{b}}$ \\
\hline 2 & Isoamylalcohol & 3-Methylbutanal & $1: 1$ & 0.5 & $90^{\mathrm{b}}$ \\
\hline 3 & 1-Octanol & Octanal & $1: 1$ & 0.5 & $85^{\mathrm{b}}$ \\
\hline 4 & Benzyl Alcohol & Benzaldehyde & $1: 1$ & 0.5 & $90^{\mathrm{b}}$ \\
\hline 5 & 2-Pentanol & 2-Pentanone & $1: 1$ & 0.5 & $93^{\mathrm{b}}$ \\
\hline 6 & Benzhydrol & Benzophenone & $1: 1$ & 1 & $80^{c}$ \\
\hline 7 & Cyclohexanol & Cyclohexanone & $1: 1$ & 2 & $95^{b}$ \\
\hline 8 & Cyclopentanol & Cyclopentanon & $1: 1$ & 1 & $95^{b}$ \\
\hline 9 & Cholesterol & 3-Oxocholesterol & $1: 1$ & 2 & $88^{c}$ \\
\hline 10 & 1-Menthol & 1-Menthone & $1: 1$ & 1 & $92^{c}$ \\
\hline 11 & Indan & 1-Indanone & $1: 3$ & 2.5 & $85^{\mathrm{c}}$ \\
\hline 12 & Tetralin & Tetralone & $1: 3$ & 2.5 & $75^{\mathrm{c}}$ \\
\hline 13 & Anthracene & $\begin{array}{l}9,10- \\
\text { Anthraquinone }\end{array}$ & $1: 3$ & 1.5 & $85^{\mathrm{c}}$ \\
\hline 14 & Phenanthrene & $\begin{array}{l}\text { Phenanthrene- } \\
9,10 \text {-quinone }\end{array}$ & $1: 3$ & 2.0 & $85^{\mathrm{c}}$ \\
\hline
\end{tabular}

Oxidations were carried out in dichloromethane at room temperature; Yields refer 2,4-DNP derivatives identified by melting points; ' $Y$ ields efer to isolated products melting points were taken directly and somparison with authetic samples (IR, TLC and NMR)

\section{RESULTS AND DISCUSSION}

This reagent was prepared by the addition of 3,4tetrahydroisoquinoline ${ }^{16}$ to a solution of an equimolar amount of $\mathrm{CrO}_{3}$ and trichloroacetic acid at $0{ }^{\circ} \mathrm{C}$ and obtained in $90 \%$ yield as an orange solid. 3,4-Dihydroisoqinolinium trichloroacetatochromate was stable when kept at room temperature for a long period of time. The infrared absorption frequencies for the trichloroacetato group at 962, 883 and $722 \mathrm{~cm}^{-1} .3,4-$ Dihydroisoqinolinium trichloroacetatochromate is soluble in polar solvent such as water, dimethyl formamide, dimethyl sulfoxide, acetone, ethylacetate, acetonitrile, but insoluble in dichloromethane, benzene, carbon tetrachloride and ether. The compound is diamagnetic tested by means of magnetic susceptibility mesurement. The compound decomposes at $100{ }^{\circ} \mathrm{C}$. The molar conductance of 3,4-dihydroisoquinolinium chlorochromate in water at $25^{\circ} \mathrm{C}$ is $140 \Omega^{-1} \mathrm{~cm}^{2} \mathrm{~mol}^{-1}$. The acidity of 3,4-dihydroisoquinolinium chlorochromate ( $\mathrm{pH}$ of a $0.01 \mathrm{M}$, solution 2.4) is less than that of $\mathrm{PCC},(\mathrm{pH}$ of a $0.01 \mathrm{M}$ solution $1.75)^{11}$ and CPCC ( $\mathrm{pH}$ of $0.01 \mathrm{M}$, solution 2.02) ${ }^{14}$.
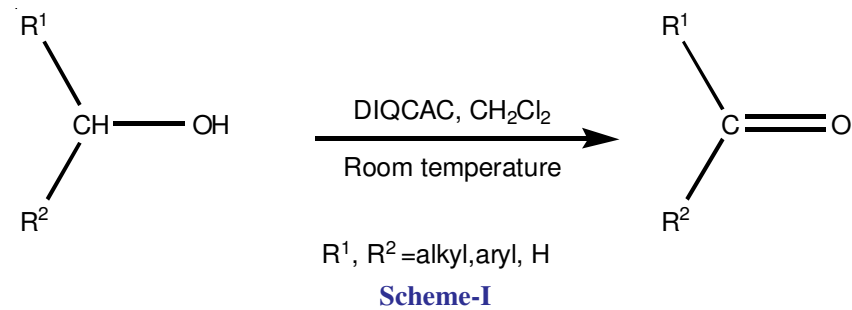

Scheme-I

This reagent can be stored as a solid for long periods without decomposition in dry medium. The structure of 3,4dihydroisoquinolinium chlorochromate was determined by infrared spectra and elemental analysis. The amount of chromium(IV) was determined by colorimetric methods using diphenylcarbazide solution ${ }^{17}$. Anal. Calc. for $\mathrm{C}_{11} \mathrm{H}_{10} \mathrm{NO}_{5} \mathrm{Cl}_{3} \mathrm{Cr}$ : Cr: $15.0_{3}$; Calc. 15.01.

As can be seen from Table-1, various substrates were tested with 3,4-dihydroisoquinolinium chlorochromate. 3,4Dihydroisoqinolinium trichloroace-tatochromate readily oxidizes primary (entires 1 to 4 ) and secondary alcohols (entires 5 to 10 ) to their corresponding carbonyl compounds in an excellent yield. 3,4-Dihydroisoqinolinium trichloroacetatochromate also oxidizes including benzylic carbon indan and tetralin $^{18}$ (entires 11 to 12 ) those converted to ketones in a good yields. In order to ascertain the efficacy of the reagent as an oxidant, it was treated with fused ring hydrocarbon anthracene and phenanthrene ${ }^{19}$ (entires 13 to 14). Anthracene and phenanthrene are oxidized to 9,10-anthraquinone and phenanthrene-9,10-quinone, respectively in good to excellent yields using substrate/oxidant ratio 1:3.

All products were characterized by ${ }^{1} \mathrm{H}$ NMR and IR spectroscopic data and their physical data compared with literature datas ${ }^{20}$.

In conclusion, 3,4-dihydroisoquinolinium chlorochromate is suitable, an inexpensive and stable solids. We have developed a practical procedure for the oxidation of alcohols to corresponding carbonyl compounds, of benzylic carbon to those ketones and of arenes to their ketones. 3,4-Dihydroisoqinolinium trichloroacetatochromate can be easily prepared and serves as an excellent oxidizing agent for various types of alcohols, benzylic carbons and arenes under non-aqueous condition at ambient temperature. After the oxidation reaction by 3,4-dihydroisoquinolinium chlorochromate, working-up such as filtration and extraction is fairly easy due to granula reduces.

\section{ACKNOWLEDGEMENTS}

Author is greatful to Mersin University Research Council and TUBITAK (The Scientific and Technical Council of Turkey for the supporting this work (Grant No: TBAG-2235). 


\section{REFERENCES}

1. Y.H. Song, Synth. Commun., 36, 631 (2006).

2. K. Sendil and B. Ozgün, Monatsh. Chem., 137, 1529 (2006).

3. B. Özgün, A. Yaylaoglu and K. Sendil, Monatsh. Chem., 138, 161 (2007).

4. K. Sendil and B. Ozgün, Phosphorus Sulfur Silicon Relat. Elem., 181, 959 (2006)

5. M.K. Chaudhuri, S.K. Dehury, S. Hussain, A. Duarah and N. Gogoi, Org. Prep. Proced. Int., 38, 331 (2006).

6. S. Ghammami and S. Sajadi, J. Serb. Soc, 70, 1243 (2005)

7. Y.-F. Zheng, X.-F. Du and W.-L. Bao, J. Chem. Res., 2005, 753 (2005)

8. (a) G. Cainelli and G. Cardillo Chromium Oxidation in Organic Chemistry, Springer-Verlag, Berlin, p. 118 (1984); J. Muzart, Chem. Rev., 92, 113 (1992).

9. J. Collins, W.W. Hess and F.J. Frank, Tetrahedron Lett., 9, 3363 (1968)

10. (a) E.J. Corey and J.W. Suggs, Tetrahedron Lett., 16, 2647 (1975); (b) E.J. Corey and G. Schmidt, Tetrahedron Lett., 20, 399 (1979); (c) E. Turunc and F. Aydin, J. Org. Prep. Proc. Int., 36, 363 (2004).
11. K. Loonker, P.K. Sharma and K.K. Banerji, J. Chem. Res. (S), 194 (1997).

12. A. Shaabani and D.G. Lee, Synth. Commun., 33, 1845 (2003).

13. M.K. Chaudhuri, K.S. Dehury, S.S. Dhar and B.U. Sinha, Synth. Commun., 34, 4077 (2004).

14. (a) M.H. Hashemi, D. Ghazaanfari and M. Akhbari, Monatsh. Chem., 135, 797 (2004); (b) A. Shaabani, A. Bazgir, F. Teimouri and D.G. Lee, Tetrahedron Lett., 43, 5165 (2002).

15. R. Ozen and A. Yurdakul, Asian J. Chem., 19, 4065 (2007).

16. J.P. Heer, J.D. Harling and M. Thompson, Synth. Commun., 32, 2555 (2002).

17. T.L. Allen, Anal. Chem., 30, 447 (1958).

18. R. Rathore, N. Saxena and S.A. Chandrasekaran, Synth. Commun., 16, 1493 (1986).

19. U. Bora, M.K. Chaudhuri, D. Dey, D. Kalita, W. Kharmawphlang and G.C. Mandal, Tetrahedron, 57, 2445 (2001)

20. L.D. Ride, CRC Handbook of Chemistry and Physics, CRC Pres Inc, Physical Constants of Organic Compounds, edn 72 (1991-1992). 